\title{
CONTRIBUTION TO THE DESIGN OF COMPRESSION MEMBERS IN AIRCRAFT
}

\author{
By Wm. R. Osgood
}

\section{ABSTRACT}

Compression members in riveted or in welded structures are columns with elastically restrained ends. Such members are usually designed as columns with a free length equal to or less than the distance between panel points. When the free length is taken as the distance between panel points, the design is likely to be safe but uneconomical. When it is taken less than this distance, however, though the economy may be evident, the safety is usually quite unknown. Bleich has shown what rational values are for the free lengths of compression members which occur in conventional types of bridges. His determination of these lengths (ratios of free length to panel-point length) is based on the theory of buckling of trusses or frameworks (Stabnetze). Unfortunately, Bleich's work does not carry over in its entirety to aircraft because some of the simplifying assumptions which he makes are not applicable here.

In this paper one of Bleich's analyses is carried a step further, resulting in a more general solution of the four-moment equation which applies to such problems.

\section{CONTENTS}

Page

I. Introduction

II. Derivation of the condition of buckling

III. Application to design

\section{INTRODUCTION}

Compression members in riveted or in welded structures are columns with elastically restrained ends. Such members are usually designed as columns with a free length equal to or less than the distance between panel points. When the free length is taken as the distance between panel points, the design is likely to be safe but uneconomical. When it is taken less than this distance, however, though the economy may be evident, the safety is usually quite unknown. Bleich ${ }^{1}$ has shown what rational values are for the free lengths of compression members which occur in conventional types of bridges. His determination of these lengths (ratios of free length to panel-point length) is based on the theory of buckling of trusses or frameworks (Stabnetze). Unfortunately, Bleich's work does not carry over in its entirety to aircraft because some of the simplifying assumptions which he makes are not applicable here. In bridges, for example, diagonal members and vertical members frequently carry primarily tension and consequently are not made stiff; they may, therefore, be neglected as contributing to the restraints at the joints at their ends.

${ }^{1}$ Fr. Bleich, Theorie und Berechnung der eisernen Brücken, Berlin, Julius Springer, 1924, and Die Knickfestigkeit elastischer Stabverbindungen, Der Eisenbau, vol. 10, pp. 27 ff., Feb. 1919. 
Corresponding members in the fuselage of an airplane, however, may be tubular and approximately as stiff as the other members meeting at the joints at their ends; to neglect such members results in a worthless analysis. It is the purpose of this paper to carry one of Bleich's analyses a step further.

\section{DERIVATION OF THE CONDITION OF BUCKLING}

Consider a loaded truss on the point of buckling in its own plane. Denote the lengths of any two of the members, $i j$ and $j k$, meeting at any joint, $\mathrm{j}$, by $l_{1 \mathrm{j}}$ and $l_{\mathrm{jk}}$, figure 1 . In general, moments will be exerted on the joints by the members. Denote by $M_{1 j}$ the moment exerted on the joint $\mathrm{i}$ by the member ij and by $M_{j 1}$ the moment exerted on the joint $\mathrm{j}$ by the member $\mathrm{ij}$, the first subscript indicating the joint acted on and the two together indicating the member acting. When the joints are fixed against translation but not against rotation, the moments in figure 1 are connected by the equation of four moments ${ }^{2}$

$$
M_{1 \mathrm{j}} s^{\prime}{ }_{1 \mathrm{j}}+M_{\mathrm{j} 1} t^{\prime}{ }_{1 \mathrm{j}}+M_{\mathrm{jk}} t^{\prime}{ }_{\mathrm{jk}}+M_{\mathrm{kj}} s^{\prime}{ }_{\mathrm{jk}}=0
$$

where

$$
\begin{aligned}
s^{\prime} & =\frac{1}{v} s(\phi), & t^{\prime} & =\frac{1}{v} t(\phi), \\
s(\phi) & =\frac{\phi}{\sin \phi}-1, & t(\phi) & =1-\frac{\phi}{\tan \phi}, \\
v & =\frac{P l}{E}, & \phi & =l \sqrt{\frac{|\bar{P}|}{E I \tau}}
\end{aligned}
$$

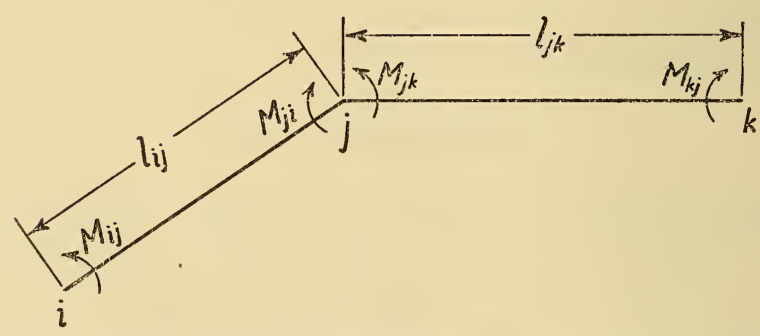

Figure 1.-Two members of a framework meeting at a common joint

$I=$ the least moment of inertia of the cross-sectional area of a member with respect to an axis perpendicular to the plane of the truss.

$\tau=\frac{\bar{E}}{E}$, the ratio of the Considère-Engesser modulus for a member to Young's modulus.

${ }^{2}$ See footnote 1; also Alfred S. Niles and Joseph S. Newell, Airplane Structures, John Wiley and Sons, Inc., New York, 1929. 
$P=$ the axial load in a member, positive when compression. If $P=0$, then $\tau=1$, and $s(\phi)=t(\phi)=0$, but $s^{\prime}=\frac{1}{6} \frac{l}{\mathrm{I}}$ and $t^{\prime}=\frac{1}{3} \frac{l}{\mathrm{I}} ;$ and if $P$ is negative, $s(\phi)=\frac{\phi}{\sinh \phi}-1, t(\phi)=1-\frac{\phi}{\tanh \phi}$.

The moments in equation 1 are positive when for an observer on one side of the members the moments tend to increase the angle on the side of the observer between the two members at any joint. The moments indicated in figure 1 are all positive for an observer below ijk.

The general method of analyzing a truss for buckling is to apply the equation of four moments successively to pairs of members meeting at joints and to determine in this way the "condition of buckling." The individual members can then be investigated, and preliminary designs may be modified.

Let it be desired to investigate a compression member $\mathrm{ij}$, figure 2 , in a riveted or a welded truss. We shall assume that the far ends of

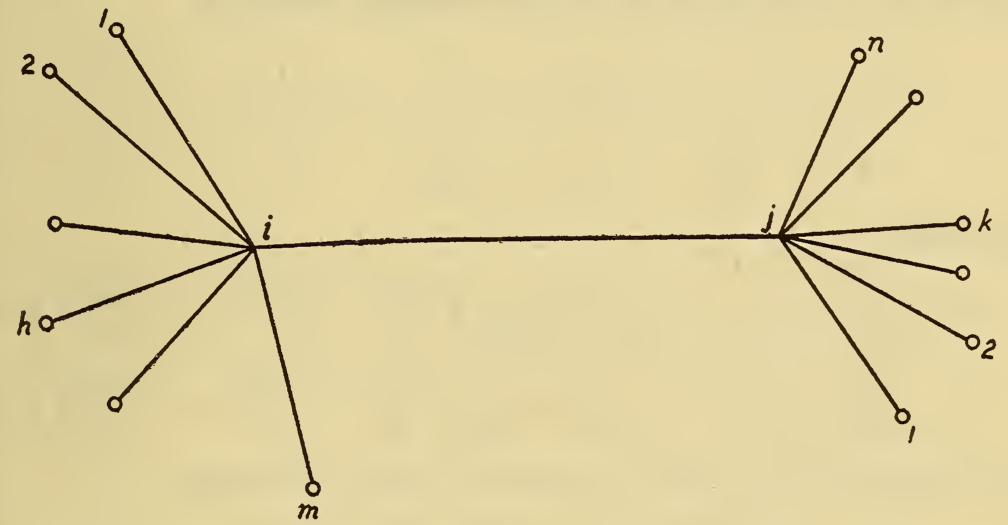

FIGURE 2.-A member of a framework together with the members meeting it at its ends.

all the members meeting at $i$ and at $j: i 1, i 2, \ldots i h, \ldots$ im and $j 1$, $\mathrm{j} 2, \ldots \mathrm{jk}, \ldots \mathrm{jn}$, respectively, except the ends of the member ij itself are freely supported. This is one of Bleich's assumptions, it is on the safe side, and some such simplifying assumption is practically necessary in all except the simplest cases. In an ideal design, as a matter of fact, the condition would be approximated closely. We shall consider moments acting on the joints positive in the counterclockwise sense. Applying the equation of four moments successively to the pairs of members $1 \mathrm{i}$ and $\mathrm{ij}, 2 \mathrm{i}$ and $\mathrm{ij}, \ldots \mathrm{mi}$ and $\mathrm{ij}, \mathrm{ij}$ and $\mathrm{j} 1, \mathrm{ij}$ and $\mathrm{j} 2, \ldots \mathrm{ij}$ and $\mathrm{jn}$, and making use of the condition of equilibrium that the sum of all the moments acting on a joint must be equal to zero, we obtain $m$ equations of the type

$$
-M_{\mathrm{ih}} t^{\prime}{ }_{\mathrm{h} 1}+M_{\mathrm{ij}} t^{\prime}{ }_{1 \mathrm{j}}-M_{\mathrm{j1}} \mathrm{s}^{\prime}{ }_{\mathrm{ij}}=0,
$$

$n$ equations of the type

64093-34-11

$$
M_{\mathrm{ij}} s^{\prime}{ }_{1 j}-M_{\mathrm{j} 1} t^{\prime}{ }_{1 \mathrm{j}}+M_{\mathrm{jk}} t^{\prime}{ }_{\mathrm{jk}}=0,
$$


and the two equations of equilibriumi

$$
\begin{aligned}
& M_{1 \mathrm{j}}+M_{\mathrm{il}}+M_{\mathrm{i} 2}+\ldots+M_{\mathrm{in}}+\ldots+M_{\mathrm{im}}=0, \\
& M_{\mathrm{j} 1}+M_{\mathrm{j} 1}+M_{\mathrm{j} 2}+\ldots+M_{\mathrm{jk}}+\ldots+M_{\mathrm{jn}}=0 .
\end{aligned}
$$

By substituting $M_{1 \mathrm{j}}$ and $M_{\mathrm{j} 1}$ from equations $6 \mathrm{a}$ and $6 \mathrm{~b}$, respectively, in equations $5 \mathrm{a}$ and $5 \mathrm{~b}$, we get $m+n$ linear homogenous equations in $m+n$ unknown moments, $m$ equations being of the form,

$$
\begin{gathered}
t^{\prime}{ }_{1 \mathrm{j}} M_{\mathrm{11}}+t^{\prime}{ }_{1 \mathrm{j}} M_{12}+\cdots+\left(t^{\prime}{ }_{1 \mathrm{j}}+t^{\prime}{ }_{\mathrm{h} 1}\right) M_{\mathrm{ih}}+\cdots+t^{\prime}{ }_{1 \mathrm{j}} M_{\mathrm{im}} \\
-s^{\prime}{ }_{1 \mathrm{j}} M_{\mathrm{j} 1}-s^{\prime}{ }_{1 \mathrm{j}} M_{\mathrm{j} 2}-\cdots-s^{\prime}{ }_{1 \mathrm{j}} M_{\mathrm{jk}}-\cdots-s{ }_{\mathrm{j}} M_{\mathrm{jn}}=0,
\end{gathered}
$$

and $n$ equations of the form,

$$
\begin{aligned}
& -s^{\prime}{ }_{1 \mathrm{j}} M_{11}-s^{\prime}{ }_{1 \mathrm{j}} M_{12}-\ldots-s^{\prime}{ }_{1 \mathrm{j}} M_{\mathrm{lh}}-\cdots-s^{\prime}{ }_{1 \mathrm{j}} M_{\mathrm{im}} \\
& +t^{\prime}{ }_{1 j} M_{\mathrm{j} 1}+t^{\prime}{ }_{1 \mathrm{j}} M_{\mathrm{j} 2}+\cdots+\left(t^{\prime}{ }_{1 \mathrm{j}}+t^{\prime}{ }_{\mathrm{jk}}\right) M_{\mathrm{jk}}+\cdots+t^{\prime}{ }_{1 \mathrm{j}} M_{\mathrm{jn}}=0 \text {. }
\end{aligned}
$$

The determinant of the coefficients of the set of $m+n$ equations, $7 \mathrm{a}$ and $7 \mathrm{~b}$, equated to zero is the condition for buckling. Upon evaluation of the determinant the condition becomes

$$
\begin{aligned}
& \left(\frac{1}{t^{\prime}{ }_{11}}+\frac{1}{t^{\prime}{ }_{12}}+\cdots+\frac{1}{t^{\prime}{ }_{1 \mathrm{~m}}}\right)\left(\frac{1}{t^{\prime}{ }_{\mathrm{j1}}}+\frac{1}{t^{\prime}{ }_{12}}+\cdots+\frac{1}{{t^{\prime}}_{\mathrm{jn}}}\right)\left({t^{\prime}}_{{ }_{1 \mathrm{j}}}{ }^{2}-{s^{\prime}}_{{ }_{1 \mathrm{j}}{ }^{2}}\right) \\
& +\left(\frac{1}{t^{\prime}{ }_{11}}+\frac{1}{t^{\prime}{ }_{12}}+\cdots+\frac{1}{t^{\prime}{ }_{1 \mathrm{~m}}}+\frac{1}{t^{\prime}{ }_{11}}+\frac{1}{t_{{ }^{\prime}}{ }_{12}}+\cdots+\frac{1}{t^{\prime}{ }_{\mathrm{jn}}}\right) t^{\prime}{ }_{1 \mathrm{j}}+1=0 .
\end{aligned}
$$

By setting

$$
\begin{aligned}
& T_{1}=\frac{1}{v_{19}}\left(\frac{1}{t^{\prime}{ }_{11}}+\frac{1}{t^{\prime}{ }_{12}}+\cdots+\frac{1}{t^{\prime}{ }_{\mathrm{Im}}}\right)=\frac{1}{P_{1 \mathrm{1}} l_{1 \mathrm{1}}}\left(\frac{P_{11} l_{11}}{t_{11}}+\frac{P_{12} l_{12}}{t_{12}}+\cdots+\frac{P_{1 \mathrm{Im}} l_{\mathrm{Im}}}{t_{\mathrm{Im}}}\right) \\
& T_{\mathrm{j}}=\frac{1}{v_{1 \mathrm{j}}}\left(\frac{1}{t^{\prime}{ }_{\mathrm{j} 1}}+\frac{1}{t_{{ }^{\prime}{ }_{2}}}+\cdots+\frac{1}{t^{\prime}{ }_{\mathrm{jn}}}\right)=\frac{1}{P_{1 \mathrm{j}} l_{\mathrm{j}}}\left(\frac{P_{\mathrm{j} 1} l_{\mathrm{j} 1}}{t_{\mathrm{j} 1}}+\frac{P_{\mathrm{j} 2} l_{\mathrm{j} 2}}{t_{\mathrm{j} 2}}+\cdots+\frac{P_{\mathrm{jn}} l_{\mathrm{jn}}}{t_{\mathrm{jn}}}\right)
\end{aligned}
$$

(see equations 2,3 , and 4 ), equation 8 may be written

$$
T_{1} T_{1}\left(t_{1 \mathrm{j}}{ }^{2}-s_{1 \mathrm{j}}{ }^{2}\right)+\left(T_{1}+T_{\mathrm{j}}\right) t_{1 \mathrm{j}}+1=0 \text {. }
$$

\section{APPLICATION TO DESIGN}

The procedure in designing should be to make a preliminary design as at present, and then by means of equations $9 \mathrm{a}$ to 10 to check the design of individual compression members (ij) and modify it if necessary. The use of equations $9 \mathrm{a}$ to 10 is facilitated greatly by a nomographic chart due to L. B. Tuckerman and by tables of values of $s$ and $t$ for $\phi$ as argument, all of which it is hoped to publish in the near future. It may be pointed out that a considerable simplification on the safe side is effected by assuming the stress in tension members to be zero.

Washington, May 18, 1934. 